\title{
Diálogos freireanos de ayer y de hoy
}

Fecha de recepción: 6 de marzo de 2020.

Fecha de aceptación: 2 de mayo de 2020.

\begin{abstract}
Resumen
A partir de los textos de Paulo Freire, se presentan diálogos —entendidos como controversias, argumentaciones, enriquecimientos - sobre la teología de la liberación, el desarrollismo, el marxismo, la pedagogía moderna, el Qué hacer de Lenin, el papel de lxs maestrxs, la conciencia y el liderazgo. Sin duda, su pensamiento puede ser objeto de críticas, y sin duda toma de la Modernidad muchos componentes, defendibles o cuestionables: el tema de la conciencia, el lugar del conocimiento científico y del docente, la división naturaleza-cultura, la división razón-emoción. Pero nada de ello disminuye su mérito de haber debatido teóricamente y ensayado - como praxis- una relación pedagógica alternativa y opuesta a la tradicional. Esto significa que los cambios en educación, incluso en el caso de una revolución como la freireana y aun cuando haya minado las bases de la educación moderna, no pueden trocar una totalidad por otra, sino que contienen elementos nuevos y viejos; de estos, algunos deberán ser desechados, pero otros perdurarán, porque al ser adecuados, o necesarios, o incompletos y abiertos a transformaciones, trascienden una época.
\end{abstract}

Palabras clave: diálogo, relación pedagógica, conciencia, praxis, liderazgo.

\section{Freirean dialogues of yesterday and today}

\begin{abstract}
Starting from Paulo Freire's texts, this article features dialogues - understood as controversies, arguments, enrichments - about liberation theology, the development theory, marxism, modern pedagogy, Lenin's What to do, the role of teachers, conscience and leadership-. No doubt his thoughts can be criticized, and he undoubtedly takes on Modernity many components, defensible or questionable: the theme of consciousness, the place of scientific knowledge, the place of teachers, the nature-culture division, the
\end{abstract}


reason-emotion division. But none of this diminishes his merit of having theoretically debated and rehearsed — as praxis - a pedagogical relationship alternative and opposite to the traditional. Which means that changes in education, even in the case of a revolution like the freirean, and even when it has undermined the bases of modern education, cannot turn a totality for another totality, but instead contain new and old elements; some of them must be discarded, but others will endure, because if they are adequate, or necessary, or incomplete and open to new transformations, they transcend an era.

Keywords: Dialogue, pedagogical relationship, conscience, praxis, leadership.

\section{Introducción}

Este trabajo es el resultado de indagaciones y reflexiones en torno de los escritos y la actividad educativa de Paulo Freire, desarrollada en ponencias y artículos académicos anteriores, pero también en clases y seminarios de grado y posgrado que nunca superaron la oralidad. ${ }^{1}$

Es imprescindible situar a Freire en la segunda mitad del siglo XX, después de la victoria sobre el fascismo, en tiempos de gobiernos "de bienestar" en unos países del globo, "socialistas" en otros, revoluciones de liberación nacional en Asia y África; y los "gobiernos populistas", los golpes de estado y la Revolución cubana en América Latina. Siglo de violencias, rebeliones culturales, desilusiones y esperanzas (Hobsbawm, 1997). Y, en este marco, la llamada "explosión educativa" (Faure, 197).

Este contexto permite entender las raíces del estrecho vínculo que establece Freire entre educación y política, extraño para una parte de lxs habitantes del siglo XXI, aunque no para otrxs.

Sin embargo, los problemas de la relación educativa entre educadores-educandos siguen vigentes, tanto como las relaciones entre gobernantes-gobernados o intelectuales-pueblo. Por eso, una de las líneas planteadas en este escrito aborda el curso de pensamiento que lleva a Freire a retomar la Tercera Tesis de Marx sobre Feuerbach y desarrollarla, así como su polémica virtual con Lenin, temas que son apenas tratados en la literatura sobre el autor y sorprenden a estudiantes y auditorios.

Este artículo se abre además a nuevos interrogantes porque lejos de permanecer acabados, los diálogos freireanos pueden y deben extenderse a las demandas del siglo XXI en nuestra región, por ejemplo en relación con ejes como la conciencia y el liderazgo.

Junto a sus textos clásicos, varios de los argumentos de este escrito se apoyan en Pedagogía de la Esperanza, un reencuentro con Pedagogía del Oprimido (1993), dado que su carácter autobiográfico permite seguir el devenir de sus ideas educativas, algunos de sus virajes y sus hitos. Pero también, evadiendo la línea histórica, en cada uno de los diálogos temáticos hay una exposición recursiva que revisita los distintos textos.

Su pensamiento fue siempre humanista y esperanzador, nunca nihilista, razón por la que continúa vigente y abre posibilidades a nuevas síntesis para abordar los tiempos actuales con bagajes vivificantes. 


\section{Afluentes teóricos}

En Estudios freireanos (1995), Carlos A. Torres sistematiza cuatro afluentes de la construcción pedagógica del autor: existencialismo, fenomenología, marxismo y filosofía hegeliana. Parece necesario destacar dos componentes más: la Teología de la Liberación y el desarrollismo.

El cruce de su pensamiento cristiano y desarrollista predomina en sus primeras obras: Educación y actualidad brasilera (1959), La educación como práctica de la libertad (1967) y ¿Extensión o comunicación? La concientización en el medio rural (1969). ${ }^{2}$ Iniciamos con ellas el recorrido de los diálogos freireanos.

\section{Diálogos desde la Teología de la Liberación}

Freire se formó en una cosmovisión religiosa, y siempre se declaró un cristiano militante. En un principio estuvo vinculado a la Iglesia Católica de su país, tan estrechamente que en 1963 la Conferencia Nacional de Obispos del Brasil adoptó de modo oficial su método de alfabetización para el Movimiento de Educación de Base (MEB).

Luego formó parte activa del movimiento de la Teología de la Liberación y participó de la elaboración del capítulo de educación del Documento de Medellín de la Conferencia Episcopal Latinoamericana (CELAM, 1968). (Barreiro, 1967; Assmann, 1969; Fiori, 1969; Hillert, 2007; Rodríguez, 2015).

En el apartado 4 del Documento de Medellín, referido a Educación, se encuentran afirmaciones disruptivas para la Iglesia, que aun después de medio siglo suenan valientes y valiosas. Sobre los pueblos originarios, el Documento de Medellín afirmaba:
La tarea de educación de estos hermanos nuestros no consiste propiamente en incorporarlos a las estructuras culturales que existen en torno de ellos, y que pueden ser también opresoras, sino en algo mucho más profundo. Consiste en capacitarlos para que ellos mismos, como autores de su propio progreso, desarrollen de una manera creativa y original un mundo cultural, acorde con su propia riqueza y que sea fruto de sus propios esfuerzos. (www.diocese-braga.pt > biblioteca > publicacoes_online, 27)

Claro que hoy no escapa al análisis que esa redacción, si bien denunciaba la opresión y convocaba al protagonismo de los pueblos aborígenes, no llamaba al diálogo intercultural sino a "capacitarlos", lo que no dejaba de ser paternalista. En punto a la educación formal, o sistemática, decía el Documento:

Los métodos didácticos están más preocupados por la transmisión de los conocimientos que por la creación entre otros valores, de un espíritu crítico. (28)

Apelar al espíritu crítico, al interior de una institución por naturaleza dogmática, era sin duda transgresor. Continuaba el Documento:

Desde el punto de vista social, los sistemas educativos están orientados al mantenimiento de las estructuras sociales y económicas imperantes, más que a su transformación. (28)

(..)

2 En las citas textuales insertadas en el texto, las obras de Freire se identifican según el año de edición de la versión utilizada. Para La educación como práctica de la libertad, 1998; para ¿Extensión o comunicación? La concientización en el medio rural, 1973a; para Pedagogía del Oprimido, 1973b; y para Pedagogía de la Esperanza, 1993. 
En especial, la formación profesional de nivel intermedio y superior, sacrifica con frecuencia la profundidad humana en aras del pragmatismo y del inmediatismo, para ajustarse a las exigencias de los mercados de trabajo. Este tipo de educación es responsable de poner a los hombres al servicio de la economía, y no esta al servicio del hombre. (28)

Más de cinco décadas después, estas ideas guardan aún toda su vigencia. Sin embargo, quedaba un largo camino por recorrer en la actualización del diálogo entre la Iglesia Católica y otras corrientes de pensamiento, entre ellas el marxismo.

Más allá de nuestra América, ese diálogo se había iniciado en las décadas de 1960 y 1970 en Europa, al calor del clima generado por el Concilio Vaticano II (19621965), a instancias del papa Juan XXIII. En ciertos casos se concretaba en espacios educativos y universitarios y algunos pedagogos tuvieron un destacado papel en su promoción. En Italia, fue organizado por el educador y matemático Lombardo Radice (Escudero, 2018).

En América Latina, fue el movimiento de la Teología de la Liberación el que dio aliento al mismo diálogo. Sobre ese periplo, Guyot publicaba en 1969, en la Revista de la Universidad Nacional de la Plata, el artículo "Libertad, trascendencia e historia en el diálogo marxista-cristiano"; yen el Aula Magna de la Facultad de Filosofía y Letras de la Universidad de Buenos Aires, el 18 de octubre de 1965, el padre Carlos Mugica inauguraba junto a otros representantes de la izquierda argentina el diálogo nacional entre católicos y marxistas.

Pero, al menos en nuestro país y en esos tiempos, dicho diálogo no llegó a un punto de madurez que permitiera la discusión sobre cuestiones educativas tales como creencias y laicismo; ni el desarrollo teórico ni el movimiento social de la época permitían alcanzar ese grado de miradas interculturales. Por eso se hace necesario reflexionar sobre esta línea freireana.

Esta problemática cobra nueva actualidad en el presente, cuando sectores políticos ortodoxos, esgrimiendo argumentos religiosos, pugnan por dejar un conjunto variado de temas fuera de la escuela, especialmente aquellos referidos a educación sexual y ciudadanía política.

Además, en momentos en que en nuestro continente afloran iglesias diversas que trabajan sobre el sentimiento religioso popular con distintas intenciones, la educación pública no puede ignorar ni dejar pasar este dato del contexto sin historizarlo, problematizarlo, incluirlo en conversaciones y debates.

La salvaguarda del laicismo y del conocimiento científico en la educación pública no descansa en el supuesto de clausurar el diálogo sobre las creencias y otras formas de conocimiento en el aula. Porque

Aunque solo una parte del saber humano puede ser 'oficializada' como conocimiento educativo, toda creencia, conocimiento o saber debería poder asomarse a la vida escolar. En particular, no debería esperarse que los educandos dejen una parte de sus culturas en las puertas de la escuela. (Hillert, 2011: 175)

Fue un profundo viraje cultural decolonial el que incorporó en 2008 tanto en la Constitución Ecuatoriana como en la Constitución del Estado Plurinacional de Bolivia la invocación a la Pachamama, cultura y creencia religiosa profundamente arraigada en sus pueblos. 
Sobre esta materia es posible retomar la ruta trazada por el pensamiento de Mariátegui, que no consideraba a las religiones solo un instrumento del poder. Decía Mariátegui en uno de sus 7 ensayos de interpretación de la realidad peruana (2007):

Han tramontado definitivamente los tiempos de apriorismo anticlerical, en que la crítica "librepensadora" se contentaba con una estéril y sumaria ejecución de todos los dogmas e iglesias, a favor del dogma y la iglesia de un "libre pensamiento" ortodoxamente ateo, laico y racionalista. El concepto de religión ha crecido en extensión y profundidad. No reduce ya la religión a una iglesia y un rito. Y reconoce a las instituciones y sentimientos religiosos una significación muy diversa de la que ingenuamente le atribuían, con radicalismo incandescente, gentes que identificaban religiosidad y "oscurantismo".

La crítica revolucionaria no regatea ni contesta ya a las religiones, y ni siquiera a las iglesias, sus servicios a la humanidad ni su lugar en la historia. (2007: 134)

Por otra parte, acerca de cómo las raíces religiosas de Freire pueden haber influido en la elaboración de su método, es útil recordar una reflexión de Gramsci:

La fuerza de las religiones, y especialmente de la iglesia católica, ha consistido y consiste en que ellas sienten enérgicamente la necesidad de la unión doctrinaria de toda la masa "religiosa" y luchan para que los estratos intelectualmente superiores no se separen de los inferiores. La iglesia romana ha sido siempre la más tenaz en la lucha por impedir que se formen "oficialmente" dos religiones: la de los "intelectuales" y la de las "almas simples". (Gramsci, 1975a: 16)

Gramsci mencionaba que desde la aparición de la Compañía de Jesús la iglesia ejerció "...una disciplina de hierro sobre los intelectuales a fin de que no pasen de ciertos límites..." (1975: 19), para no aumentar su distancia con los simples.

En nuestro país, al denunciar posturas que sí aumentaban las distancias entre el pueblo y ciertos intelectuales a los que bautizó como "intelligentzia", decía Jauretche:

Los ilustrados reaccionan con su íntima estructura de hombres de la "parte principal" de la población y no pueden admitir — en cuanto se les opone — la presencia como actora de la parte de la sociedad que, como clase, ven solo en "plebe o chusma". (1973: 289)

En el caso de Freire, esta vocación de desplegar el diálogo entre "los intelectuales" y "el pueblo", nutrida desde la Teología de la Liberación y otros movimientos políticos y culturales de su tiempo, fue el interés vector de su pedagogía y de su método.

\section{Diálogos desde el desarrollismo}

Otro afluente de su marco conceptual se gestó en su contacto con el ISEB (Instituto Superior de Estudios Brasileros) en el que entonces predominaban las ideas desarrollistas; y desde donde, algunos años después, formularon la teoría de la dependencia intelectuales como Darcy Ribeiro, Fernando Henrique Cardozo, Celso Furtado y Theotonio Dos Santos (Hillert, 2008). Más adelante, en el presente siglo, ante nuevos giros de la historia, estos mismos pensadores asumirían posicionamientos políticos distintos y divergentes.

Los planteos desarrollistas no se referían a formas de desarrollo diversas, ni a formas de propiedad alternativas o mixtas; suponían el comienzo de una época y una fase esperanzada de progreso focalizada en la necesidad de la industrialización capitalista 
como único camino; período siempre acompañado de la necesidad de confluencia de distintas clases sociales, que Paiva denominó "nacionalismo desarrollista" (1982: 38).

Las páginas de La educación como práctica de la libertad tienen entre sus bases teóricas el texto de Karl Popper La sociedad abierta y sus enemigos (1945). Popper abordó teóricamente la transición de las sociedades cerradas a las sociedades abiertas — desde una posición evolucionista-; y, tomando partido por Occidente en el marco de la guerra fría, señaló el peligro de los totalitarismos que intentaban retroceder desde las civilizaciones contemporáneas — entiéndase capitalistas - abiertas, hacia sociedades anteriores, cerradas.

Consustanciado con los principios desarrollistas del ISEB, Freire organizó los capítulos de La educación como práctica de la libertad tomando los conceptos de sociedad abierta y sociedad cerrada, y mencionando a Popper en la autoría de estas ideas.

Este era un núcleo temático de la época, al punto que en la carrera de Sociología de la Universidad de Buenos Aires, Gino Germani y Jorge Graciarena publicaron en 1964 la antología De la sociedad tradicional a la sociedad de masas, en la que reunieron textos sobre ruralidad, urbanización, industrialización, demografía, familia, vida tradicional y tercerización.

Una producción intelectual en paralelo como la descripta, respondía a que en la década de 1950, en la Argentina y en Brasil se producían fenómenos semejantes de industrialización y migración interna del campo a la ciudad, y los académicos de ambos países analizaban las implicancias económicas, políticas y culturales de estos cambios.

Los trabajos de Germani describieron a las sociedades tradicionales o preindustriales, rurales, como sociedades con economías de subsistencia, basadas en actividades agrícolas primarias, con fuerte peso de la economía doméstica y la producción artesanal; con familias extensas, firme autoridad de los ancianos, costumbres rígidas, relaciones interpersonales restringidas sobre todo al interior del grupo primario o endogrupo. El clima de control comunitario negaba la individuación. Este tipo de sociedades encontraba un sustento importante en la religión.

Como contracara le sucedía, en una línea planteada como evolutiva, la sociedad industrial urbana, abierta, de familia nuclear, con procesos de individuación y especializaciones profesionales; el grupo primario perdía importancia frente a los grupos secundarios, la economía pasaba a ser mercantil, se incentivaba el consumo a través de la publicidad; aparecían la competencia, las aspiraciones de éxito y las posibilidades de movilidad vertical y horizontal. Se producía una laicización de la vida en la cual la religión perdía importancia.

Sobre la base del esquema subdesarrollo-desarrollo, en La educación como práctica de la libertad, antes de exponer su metodología y sus primeras experiencias de alfabetización de adultos en el nordeste brasilero, Freire describió la sociedad cerrada y la sociedad abierta en las condiciones de Brasil. Sostuvo que la educación de las masas era absolutamente fundamental para los países subdesarrollados del Tercer Mundo, porque la industrialización, principal fuerza de destrucción de la sociedad cerrada (Freire, 1998: 39), reclamaba un cambio de mentalidad que incrementara la esfera intelectual y redujera la instintiva-emocional (ibídem: 35). Se hacía indispensable una amplia concienciación, una "elevación del pensamiento" de las masas, para su inserción en la historia, ya no como espectadoras sino como actoras y autoras (ibídem: 26).

Enormes esperanzas y tareas se depositaban en la educación: la industrialización podía llevar a la deshumanización, y la educación debía evitarlo; la educación debía favorecer 
el funcionamiento de una sociedad abierta, democrática, e impedir la domesticación, la masificación; la educación debía formar una conciencia crítica, porque cuanto más crítico fuera un grupo humano, tanto más permeable y flexible sería. Esta debía ser una educación "para el cambio y la liberación".

En La educación como práctica de la libertad, Freire trabajó a fondo el tema de las conciencias, y culminó proponiendo una educación activa, dialogal, crítica, participante, para la concienciación.

En su crítica a Freire, Kush señaló que la euforia desarrollista de las décadas de 1950 y 1960 se había propuesto "mutar el ethos" popular y que también Paulo Freire participaba de esa aspiración de cambiarlo mediante la educación. Una mutación dirigida a occidentalizar al campesino, porque la urgencia del desarrollo pretendía incorporarlo a la vida económica de la ciudad.

Kush criticó también el sistema binario de clasificación de Freire: hombre-naturaleza; doxa-logos; magia-ciencia. En el campo del conocimiento, Kush se preguntaba si se conocían con toda exactitud los límites que separaban a la magia de la ciencia (Kusch, 2000: 112 y ss.).

Algunas décadas después, el pensamiento social nos suscita nuevos desafíos y algunas pocas síntesis: hoy podemos proponernos construir un humanismo no antropocéntrico, reconocemos que racional no es igual a racionalismo a ultranza y a racionalización, que a la teoría le faltan respuestas sobre las emociones y la psicología social; que nuestro conocimiento siempre será finito en un océano de desconocimiento infinito; que la ciencia debe ser acompañada de sabiduría y de prudencia; que junto al conocimiento científico existen otros conocimientos, entre ellos los éticos y artísticos; que las creencias, incluidas las religiosas, son dimensiones ineludibles de toda sociedad. Pero también, que para los problemas científicos las soluciones deben ser científicas, y que el pensamiento mágico tiene aristas que lo ligan al fanatismo. Por eso, aunque sus afirmaciones no sean siempre plausibles, celebramos que Freire continúe invitándonos a no concebir respuestas simples para asuntos complejos, continúe invitándonos a problematizar.

\section{Diálogos con la pedagogía moderna y el marxismo}

El principal aporte pedagógico de Freire consiste en haber planteado la posibilidad del diálogo como relación horizontal de A más B. El diálogo, escribió Freire, "Es una relación horizontal de A con B. Nace de una matriz crítica y genera criticidad (Jaspers)". El antidiálogo, en cambio, supone una relación vertical de A sobre B. "Es acrítico y no genera criticidad." (1998: 104-105).

Esta formulación opera un giro copernicano en el modelo educativo de la Modernidad montado desde el siglo XVII, que concebía siempre al educador, paternal o maternalmente, sobre, por encima del educando.

Un poco después de La educación como práctica de la libertad, en el texto ¿Extensión o comunicación?, el capítulo "La educación como una situación gnoseológica" comenzaba con la Tercera Tesis de Marx sobre Feuerbach, escrita entre 1845 y 1846 (Freire, 1973a: 85). La misma Tesis se cita en el Capítulo 1 de Pedagogía del Oprimido (1973b: 52). Marx argumentaba:

La teoría materialista de que los hombres son producto de las circunstancias y de la educación, y de que, por lo tanto, los hombres modificados son producto de circunstancias distintas y de una educación distinta, olvida que son los hombres quienes 
cambian las circunstancias y que el propio educador necesita ser educado. Conduce, pues, forzosamente, a la división de la sociedad en dos partes, una de las cuales está por encima de la sociedad (así, por ejemplo, en Robert Owen). La coincidencia de la modificación de las circunstancias y de la actividad humana solo pueden concebirse y entenderse racionalmente como práctica revolucionaria. (Marx, 1973: 9)

Marx enunciaba así, probablemente por primera vez, un problema milenario, que la educación burguesa convirtió en dispositivo generalizado, y que tuvo continuidad en las experiencias socialistas del siglo XX. Pero enunciar el problema no era igual a resolverlo (Hillert, 2001). En Marx el debate remitía al plano político, y su resolución a la praxis revolucionaria.

En el terreno educativo, Freire sostuvo en Pedagogía del Oprimido (1969) que la educación problematizadora reclamaba “...la exigencia de la superación de la contradicción educador-educando".

Fue Freire quien en su trayectoria educativa efectuó la búsqueda y encontró una respuesta —entre otras quizás posibles—, teórico-práctica, a un problema que Marx había dejado planteado, y cuya cuestión más aguda es quién educará al educador, o cómo se educa el educador.

Freire inició la revisión propositiva del modelo moderno y ensayó una educación emancipatoria, fundida en una matriz distinta a la del siglo XVII. Esta revolución pedagógica tuvo lugar en el territorio nuestroamericano, en nuestra geografía. Aquí desocultó las voces de quienes viven en el silencio y reconoció la dignidad y los saberes de quien aprende, antes de continuar su tarea educativa junto a los movimientos de liberación nacional y los estados recientemente liberados de Asia, África y Oceanía. ${ }^{3}$

No fue casual que este giro en el modelo de la pedagogía se diera en ese momento y en nuestro continente. La década de 1960 había marcado un cambio político y cultural en todo el planeta que tuvo como punto culminante el mayo-junio francés. Para nosotrxs, en lo político y social fueron los años de la Revolución cubana de 1959 y de la mencionada Conferencia Episcopal Latinoamericana de Medellín en 1968; también del golpe de estado en Brasil de 1964 y del triunfo de Salvador Allende en Chile en 1970. En lo cultural, los años del boom de nuestra literatura -García Márquez, Carpentier, Cortázar, Roa Bastos, Vargas Llosa, Benedetti-. En la Argentina nacían el movimiento del Nuevo Cancionero folclórico y el rock nacional, y en 1965 Ariel Ramírez daba a conocer la Misa criolla.

\section{Diálogos con el Qué hacer}

En Pedagogía del Oprimido se constata un pasaje de Freire desde el desarrollismo hacia la teoría de la dependencia y el marxismo. ¿Cómo se generó ese movimiento en la cosmovisión freireana?

Exiliado, Freire vivió en Chile durante la presidencia demócrata cristiana de Eduardo Frei, antes del triunfo de la Unidad Popular encabezado por Salvador Allende, socialista, en 1970. 
Diversos autores (Rodríguez, 2004, 2015; Gajardo, 2016) coinciden en que en ese contexto se produjo la aproximación de Freire a categorías y enfoques marxistas; pasó del planteo del desarrollo a la comprensión de los conflictos entre clases sociales, y a la comprensión del problema de las dependencias externas e internas entre centros y metrópolis en nuestros países. Esta transición seguía también los pasos de la intelectualidad avanzada de Brasil, de los autores de la "teoría de la dependencia".

Sobre ese período, vivido en Chile entre fines de 1964 y principios de 1969, relató el mismo Freire en Pedagogía de la Esperanza:

\begin{abstract}
Habría sido verdaderamente imposible vivir un proceso políticamente tan rico, tan problematizador, haber sido tocado tan profundamente por el clima de acelerados cambios, haber participado en discusiones animadas y vivas en "círculos de cultura" (...) sin que todo eso llegara a expresarse después en tal o cual posición teórica defendida en el libro que en aquella época no era ni siquiera proyecto. (1993: 37)
\end{abstract}

La radicalización de las posiciones de Freire se expresó en especial en Pedagogía del Oprimido. Freire relata que comenzó a trabajar en esa obra entre 1967 y 1968, en parte en forma oral, gracias a conversaciones con amigos, en parte tomando apuntes sobre ideas y experiencias, escribiendo y ordenando fichas; y que luego en quince días y de un solo impulso dactilografió los tres primeros capítulos, los dio a leer a colegas y aceptó el consejo de dejarlos "en cuarentena" por un par de meses. Al releerlos, reconoció: “... hice el fundamental descubrimiento de que no estaba acabado. Necesitaba un capítulo más." (1993: 57). Así nació el Capítulo IV.

En la malla de este capítulo encontramos referencias político-educativas a la Revolución cubana, a la figura del Che, a la Revolución cultural china y al liderazgo en general. El Capítulo IV de Pedagogía del Oprimido es un caldero en el que fermenta la naturaleza política de la educación y la necesidad de hacer a la política más pedagógica.

Colocar a la educación en el centro de múltiples ilaciones sociales nos trae a la memoria una conocida reflexión de Gramsci:

(...) la relación pedagógica no puede ser reducida a relaciones específicamente "escolares"... Esta relación se da... entre capas intelectuales y no intelectuales; entre gobernantes y gobernados; entre elites y adherentes; entre dirigentes y dirigidos; entre vanguardias y cuerpos de ejército. Cada relación de "hegemonía" es necesariamente una relación pedagógica... (Gramsci, 1975: 34)

No es extraño que la experiencia de Freire, hasta ese momento fuera del ámbito del sistema escolar y en contacto con los procesos sociales y políticos de América Latina, lo llevaran a pensar la relación pedagógica al interior de los conflictos nuestroamericanos.

Pero la sorpresa del Capítulo IV consiste en que está claramente orientado al debate con la pedagogía planteada por Lenin en el Qué hacer, escrito en 1902 - hace casi ciento veinte años-, que puede ser considerado un modelo teórico de educación y que propone inculcar contenidos socialistas bajo la matriz de la pedagogía moderna, paternalista y unidireccional.

El Capítulo IV de Pedagogía del Oprimido - escrito hace más de cincuenta añoscomienza mencionando esa obra de modo explícito: al aludir en forma elogiosa a la afirmación de Lenin "Sin teoría revolucionaria, no puede haber tampoco movimiento revolucionario", Freire incluyó una llamada a pie de página para citar 
como fuente el Qué hacer ${ }^{4}$ (1973b: 162). E inmediatamente dio inicio a un análisis que anticipaba la crítica que desplegaría sobre el Qué hacer a lo largo de todo el capítulo, con estas palabras:

El esfuerzo revolucionario de transformación radical de estas estructuras no puede tener, en el liderazgo a los hombres del que hacer y en las masas oprimidas hombres reducidos al mero hacer. (1973b: 162)

El liderazgo no debía "regar" de conocimiento a los oprimidos, ni considerarlos meros ejecutores de sus determinaciones. Esta era una respuesta a Lenin quien, en su proyecto de partido, se basaba en los principios de la pedagogía tradicional. En la propuesta de Lenin se concretaba una vez más el modelo denunciado por Marx, de una sociedad dividida en dos partes, una de las cuales se considera a sí misma por encima de la otra: la llamada "vanguardia", o "educadora".

Freire, al tiempo que ponderaba a Lenin, sentaba las bases de una educación emancipatoria, opuesta al dispositivo moderno. Entre Freire y Lenin es posible establecer un diálogo, virtual, puesto que no fueron contemporáneos. ${ }^{6}$

En relación con los orígenes y la transmisión del conocimiento, el modelo moderno, adoptado en el Qué hacer, seguía la línea kantiana: el conocimiento es elaborado por los filósofos y difundido al público a través de un cuerpo de especialistas. ${ }^{7}$

Freire y Lenin comparten puntos de vista críticos y modernos. Pero Freire rechaza que el conocimiento acerca de las transformaciones necesarias, sus caminos y sus métodos, sea "entregado" o "donado" como sucede en la concepción bancaria (Hillert, 2007).

Lenin consideraba al marxismo como conocimiento acabado y armónico, todopoderoso por ser cierto. Defendió repetidamente la aspiración de resolver primero los problemas en la teoría, para luego convencer de la justeza de esa solución al partido y a las masas (Lenin, 1959: 403).

Sin embargo, Lenin no dejó de otorgar un papel relevante también a la práctica, con toda su carga de emociones y sentimientos. Sostuvo que las ideas claras sobre quiénes son amigos y quiénes enemigos, o sobre el carácter de la autocracia, no saldrían de los libros, sino de la educación en la acción, en la actividad revolucionaria (Lenin, 1959: 419-422). En el análisis de muchas situaciones de conflicto social reconoció no solo los componentes racionales sino también los afectivos: percibía cuándo los obreros luchaban movidos por la desesperación y el deseo de venganza, llamaba a movilizarse con decisión y abnegación, señalaba que era tan necesario comprender como sentir, sentir como comprender, y él mismo concibió y dirigió la Revolución rusa durante una vida breve, aunque ardiente e inflamada de pasiones (Hillert, 2007).

Pero entre todos los saberes, el marxismo privilegió la ciencia, la teoría, el racionalismo, como cúspide del conocimiento humano. Fueron insistentes los postulados leninistas en este sentido: el socialismo se ha convertido en ciencia y es necesario tratarlo como

\footnotetext{
4 Años después, el pedagogo francés George Snyders hizo un análisis en general aprobatorio y acrítico del Qué hacer (1979). 5 Para Gramsci, el rol del educador o del moderno Príncipe es ejercido por todo aquel que tiene una posición dirigente en la sociedad, sea el Estado, el partido, la vanguardia, el padre, el legislador, el docente (Gramsci, 1975b).

6 Para la continuidad de la lectura, se especifican los años de vida de los autores incluidos en este debate o intercambio hipotético: Lenin, 1870-1924; Gramsci, 1891-1937; Freire, 1921-1997.

7 Kant había escrito: "En una palabra: la ciencia (buscada con crítica e iniciada con método) es la puerta estrecha que conduce a la sabiduría, (...) una ciencia cuya guardiana debe seguir siendo siempre la filosofía, en cuyas sutiles investigaciones no debe intervenir para nada el público, aunque sí debe interesarse por las doctrinas que son las que podrán ilustrarlo con la debida claridad después de haber sido elaboradas de este modo." (Kant, 1993: 173)
} 
tal, es decir, estudiarlo; el conocimiento dirige la práctica, se aplica a la práctica, sin teoría revolucionaria no puede haber actividad revolucionaria consecuente; este conocimiento no puede sino venir de afuera de la experiencia obrera y popular espontánea, del campo de la intelectualidad. Como corolario de esta serie, Lenin sostenía que el marxismo educa al partido, y el partido educa a las masas. La vanguardia juega un papel educador, para hacer penetrar la conciencia en el movimiento espontáneo; la vanguardia debe elaborar un programa y un plan táctico, y ganar - conquistar-para ellos a las masas. Todas esas afirmaciones leninistas pertenecen al modelo pedagógico de la relación vertical de A sobre B.

Freire no negaba la necesidad de un programa, pero se oponía a la programación vertical, ya fuera en programas políticos o docentes (1973b: 113). No negaba la necesidad de la teoría, pero aseguraba que una teoría de la liberación debía ser construida en el encuentro entre liderazgo y pueblo (1973b: 242). Y acerca del término "conquistar", respondió en el Capítulo IV: "Al revolucionario le cabe liberar y liberarse con el pueblo y no conquistarlo" (114).

En las primeras décadas del siglo XXI, las experiencias que atraviesan tanto a los nuevos movimientos sociales como a las direcciones sindicales, a la educación escolar y a la vida académica universitaria, $y$ hasta a los liderazgos de los gobiernos nacionales y populares, ponen dramáticamente en evidencia la crisis del verticalismo y del autoritarismo, y la necesidad de aprender relaciones horizontales, dialógicas, de conducción.

En el contexto de la Rusia prerrevolucionaria, pero desde otro extremo teórico, desde posiciones basistas, los populistas rusos de fines del siglo XIX y principios del siglo XX consideraban que la sabiduría residía en el pueblo, en el alma o el corazón del pueblo, y que era necesario dirigirse a las aldeas a aprender del pueblo. Paiva sostuvo que el populismo ruso, bajo la influencia del romanticismo alemán, defendía la "bondad natural" de los campesinos, y el "cristianismo innato" del pueblo; se oponía al racionalismo iluminista; promovía que los intelectuales - los estudiantes entre ellos - se contactaran vivencialmente con la historia y las costumbres de la población. Los jóvenes católicos brasileros del MEB de la década de 1960 asumieron como propios estos elementos ideológicos (Paiva, 1982).

El modelo pedagógico leninista, asimétrico, no nació con el leninismo. No obstante, parecía ser el único posible ante la envergadura de la revolución inminente y el cuadro de la desigualdad educativa real en la Rusia zarista. Porque el $80 \%$ de los habitantes era analfabeto y en algunas regiones el índice llegaba hasta el 95\%. Un semanario especializado sostenía en 1906 que liquidar el analfabetismo en Asia Central, donde muchas lenguas carecían de alfabeto gráfico, insumiría 2.600 años. Siguiendo este cálculo, ese objetivo habría sido cumplido hacia el año 4506 de nuestra era. El socialismo resolvió en lo fundamental esta situación antes de la Segunda Guerra Mundial (Hillert, 2007; Carbonell, 2017).

En 1902, para encarar la lucha teórica, ideológica, Lenin tomó como modelo de educador la figura del tribuno, del orador que debía denunciar las injusticias, los atropellos y trabajar como difusor de las nuevas ideas. Su discurso era unidireccional, las masas recibían el mensaje transmitido en forma de agitación y propaganda, de consignas.

Colocar a las masas a disposición de la organización de vanguardia, introducir o hacer penetrar la ideología - ambos enunciados misóginos-, conquistar las conciencias, fueron el lenguaje y la visión del Qué Hacer sobre este problema, lenguaje que hoy ha sido rechazado y superado: en el último tercio del siglo XX, por la crítica freireana en el Capítulo IV de Pedagogía del Oprimido; en el siglo XXI rechazado también por cuestiones de género. 
Sin haber manifestado que estaba criticando el Qué hacer, por el contrario, expresando su admiración hacia Lenin y sus páginas, Freire diría que esa pedagogía, en la cual el educando es pasivo, receptáculo, reproducía los métodos de conquista, colonización, dominación, y no podía dar por resultado desalienación o emancipación. Y recalcaba que no era a través de la propaganda que los oprimidos llegarían a insertarse críticamente en la lucha, como sujetos y no como objetos (Freire, 1973b: 70). Por eso proponía avanzar desde la palabra, como conciencia, hacia la palabra-acción -o praxis. ${ }^{8}$

Sostenía que una revolución que no lograra revolucionar la cultura, se dirigía al fracaso. En cambio quien se propusiera modificar no solo la ideología sino también la vida y la acción - es decir, la hegemonía en términos gramscianos- ${ }^{9}$ debería realizar un largo trabajo cultural. A eso se dirigía la obra de Freire.

Cuando reflexionaba acerca del uso de la palabra en el marco de distintas dominaciones y opresiones, se preguntaba cómo podía haber diálogo desde una actitud arrogante, autosuficiente, diálogo sin humildad; cómo podía haber diálogo si se veía solo la ignorancia del otro, y no la propia; y especialmente,

¿Cómo puedo dialogar, si me admito como un hombre diferente, virtuoso por herencia, frente a los otros, meros objetos en quienes no reconozco otros "yo"? ¿Cómo puedo dialogar si me siento participante de un "ghetto" de hombres puros, dueños de la verdad y del saber, para quien todos los que están fuera son "esa gente" o son "nativos inferiores"? (1973b: 107)

Y:

(...) el sectarismo tiene una matriz preponderantemente emocional y acrítica, es arrogante, antidialogal y por eso anticomunicativo. (1998: 42)

Algunos de los temas examinados en los subtítulos del Capítulo IV son quehacer y hacer, teoría, liderazgo y ejecutores, praxis del liderazgo y praxis de las masas, mesianismo, dominación, conquista, manipulación, sectarismo, burocracia, esloganización, depósito, conducción, prescripción, responsabilidad coordinadora y en ciertos momentos directiva, diálogo, comunicación, conciencia crítica, problematización.

Desde estos conceptos Freire construyó su defensa del carácter pedagógico de la revolución entendida como acción cultural para la liberación (1973b: 177).

\section{Diálogos sobre la conciencia}

Junto a la propuesta de educación dialogal o relación horizontal de $\mathrm{A}+\mathrm{B}$, el tema pedagógico principal en el que Freire se sumergió en Educación como práctica de la libertad y continuó en Pedagogía del Oprimido y en Acción cultural para la libertad fue, sin duda, el de la conciencia.

En relación con sus experiencias de alfabetización en el nordeste brasileño en contacto con poblaciones campesinas, Freire negaba que el campesino fuera ignorante, afirmaba

8 En sus escritos sobre Ixs intelectuales Gramsci diferenció a Ixs intelectuales tradicionales, caracterizadxs por su elocuencia verbal, de Ixs nuevxs intelectuales vinculados a la técnica y a la producción, a la praxis; estxs nuevxs intelectuales no construyen un nexo ideológico entre gobernantes y gobernadxs, sino un nexo productivo con los trabajadores. Pero deberían vincular técnica, ciencia, humanismo, para ser no solo especialistas sino también dirigentes.

9 Fue Gramsci quien desarrolló la noción de hegemonía no solo en su sentido político, sino especialmente como hegemonía intelectual y moral, como hegemonía cultural. El replanteo de Freire no hubiera sido posible sin los aportes de Gramsci. Aunque sus ideas le hayan llegado muchas veces indirectamente, Freire dijo reconocerse en Gramsci, sentir que habían trabajado en paralelo temas idénticos. Pero Lenin no pudo haber leído a Gramsci. 
e insistía en que no existe ni ignorancia ni sabiduría absolutas. Pero sí distinguió grados de conocimiento (1998: 52) o niveles de conciencia (1975: 85)..$^{10}$ Este también es un tema totalmente moderno.

Había en Freire una alta valoración de la razón sobre lo emocional - a mayor racionalidad, menor emocionalidad - lo que lo ubica nuevamente y en forma decisiva en el campo de la Modernidad.

Esto se constata en varios pasajes en que vinculaba la emocionalidad al irracionalismo, al fanatismo, al sectarismo, a la incapacidad de argumentaciones serenas, en los que ciertamente quedaba plasmada una problemática aun vigente y en debate.

Estas formas de pensamiento, de acuerdo con estudios previos de Vieira Pinto y Azevedo (Rodríguez, 2015), correspondían a la conciencia intransitiva, propia de la sociedad campesina.

Pero la urbanización y la industrialización habían quebrado la conciencia intransitiva, y habían dado lugar a la conciencia transitiva, en un principio ingenua. El pasaje de la transitividad ingenua a la transitividad crítica era posible solo con un trabajo educativo crítico.

Para generar conciencia crítica, era necesario ir "...al encuentro de ese pueblo que ya emerge en los centros urbanos y lo está intentando en los rurales..." (Freire, 1998: 51).

La conciencia crítica, argumentaba Freire, se caracteriza por la profundidad en la interpretación de los problemas, la búsqueda de la causalidad y el descreimiento en las magias, la ruptura con los preconceptos aceptando comprobaciones y revisiones, el ejercicio del diálogo en lugar de la polémica, y por ello la capacidad de la argumentación. La receptividad de lo nuevo y la no negación de lo viejo simplemente por viejo. Este tipo de pensamiento debía favorecer los debates y la participación ${ }^{11}$ en los códigos de la democracia. ${ }^{12}$

Cuando Freire hizo su autocrítica con respecto al tema de la concientización, no se refería a la negación de la necesidad de una mayor conciencia, sino a la necesidad de unir la conciencia con la acción, con la praxis; a la comprensión de que el conocimiento necesario para la transformación no consistía solo en la liberación de la conciencia, sino en una práctica social liberadora (Gajardo, 2016). Su autocrítica se dirigía a entender la libertad no solo como conciencia de la necesidad, sino como capacidad de movilización emancipatoria.

\section{Diálogos con lxs maestrxs}

Sostener que el pasaje de la conciencia ingenua a la conciencia crítica solo puede realizarse mediante la educación, equivalía a afirmar que hacían falta maestrxs, que lxs maestrxs son imprescindibles.

10 El capítulo V de Acción cultural para la libertad se titula "Condicionamiento histórico y niveles de conciencia".

11 Existen evidentes puntos de contacto entre estos argumentos de Freire y los postulados por Habermas, en su Teoría de la acción comunicativa (1987). Pero los diferencia el hecho de que Freire propone el diálogo entre quienes integran el campo popular, dentro de su interior; y subraya que el diálogo es imposible con el enemigo, con el antagonista.

12 La actualidad del tema de la conciencia adquiere toda su dimensión en el análisis de los acontecimientos de la Argentina entre 2015 y 2020 , cuando un importante sector de la población optó por el neoliberalismo, aun en contra de sus propios intereses, por influencia de los medios y la conformación de un núcleo de opinión pública que propugnaba un concepto inmediatista e individualista de libertad y felicidad. Lo cual confirma que la asunción de la conciencia crítica no es espontánea. 
Haber manifestado que "Ahora, ya nadie educa a nadie..." o que la relación educadoreducando debía ser horizontal, no conducía al espontaneísmo. Decía Freire:

El diálogo entre profesoras o profesores y alumnos o alumnas no los convierte en iguales, pero marca la posición democrática entre ellos o ellas. Los profesores no son iguales a los alumnos por "n" razones, entre ellas porque la diferencia entre ellos los hace ser como están siendo. Si fuesen iguales, uno se convertiría en el otro. El diálogo gana significado precisamente porque los sujetos dialógicos no solo conservan su identidad, sino que la defienden y así crecen uno con el otro. (Freire, 1993: 112)

Además, Freire valoraba la seriedad y calidad de la transmisión de los contenidos de conocimiento:

(...) es imposible la eficacia de un curso de física en el cual el profesor no sepa física. Nadie enseña lo que no sabe. ${ }^{33}$ Pero tampoco nadie, dentro de una perspectiva democrática, debería enseñar lo que sabe sin saber lo que saben, y en qué nivel, aquellos y aquellas a quienes va a enseñar lo que sabe." (1993: 125)

Los rasgos que adjudica a quien opta por una posición radicalizada, avanzada, bien podrían aplicarse al educador:

El hombre radical en su opción no niega el derecho a otro de optar. No pretende imponer su opción, dialoga sobre ella. Está convencido de su acierto, pero respeta en otro el derecho de juzgarse también dueño de la verdad; intenta convencer y convertir, pero no oprime a su oponente... (Freire, 1998: 41)

Convencido de la necesidad de existencia de lxs educadorxs, escribió en 1994 sus Cartas a quien pretende enseñar. En cada una de ellas abordabs un tema referido a la escuela, al aula o a la enseñanza. La Cuarta Carta, por ejemplo, trata "De las cualidades indispensables para el mejor desempeño de las maestras y los maestros progresistas". En la misma recomienda la "humildad", para reconocer que "....nadie lo sabe todo, nadie lo ignora todo". La "amorosidad", la "valentía" de luchar, junto a la valentía de amar. La "superación del miedo"; la "tolerancia" para convivir con lo que es diferente; el ejercicio de su "autoridad"; "el estímulo y la lucha por la alegría en la escuela", y la defensa del

Derecho a su libertad docente, derecho a hablar, derecho a mejores condiciones de trabajo pedagógico, derecho a un tiempo libre remunerado para dedicarse a su permanente capacitación, derecho a ser coherente, derecho a criticar a las autoridades sin miedo de ser castigados - a lo que corresponde el deber de responsabilizarse por la veracidad de sus críticas-, derecho a tener el deber de ser serios, coherentes, a no mentir para sobrevivir. (Freire, 1994: 71)

Estas posiciones de Freire sobre lxs maestrxs son muy distintas y distantes a las que levanta el neoliberalismo. Como escribiera Tatián en nuestro país, el neoliberalismo “...embiste contra la docencia como práctica social, sobre todo, porque hay en ella algo irreductible a ese régimen". La docencia, dice el autor, es irreductible a la mercancía, es algo que no tiene precio, y que produce una interrupción económica, cultural y social en el orden capitalista (Tatián, 2017). 


\section{Diálogos sobre el liderazgo}

En Pedagogía del Oprimido Freire trabajó con toda seriedad y compromiso el problema del liderazgo, muy lejos de la banalidad y el divertimento con que el neoliberalismo ha abordado el tema en los últimos años.

Freire no admitía una "posición liberalista..." de ausencia de dirección. La transformación revolucionaria solo podía ser realizada "por los oprimidos con un liderazgo lúcido" (Freire, 1973b: 168). No rechazó la organización ni la disciplina: "Sin liderazgo, disciplina, orden, decisión, objetivos, tareas que cumplir y cuentas que rendir, no existe organización, y sin esta se diluye la acción revolucionaria" (ibídem: 234). Pero sostenía que un liderazgo "que insiste en imponer su palabra de orden", "no libera ni se libera, simplemente oprime".

Señalaba que si hay "manipulación", "esloganización”, “depósito", hay una contradicción entre las formas y los objetivos que se pretenden alcanzar. Y por los caminos de la opresión, la manipulación, la cosificación de las masas, “...el liderazgo o no hace la revolución o si la hace, esta no es verdadera” (ibídem: 217).

Cuando criticaba las consignas, los eslóganes, los decretos, denunciaba el dirigismo de un liderazgo que había desarrollado "...el poder o el gusto de mandar, de dirigir, de comandar". Que "Ya no puede vivir si no tiene a alguien a quien dirigir su palabra de mando" (ibídem: 174). Eso le permitió diferenciar entre "un pensamiento de señor" y "un pensamiento de compañero" (ibídem: 172).

Distintos pasajes y expresiones como estas evidencian que en el pensamiento freireano la relación educativa entre educando-educador equivale a la relación política entre gobernantes-gobernadxos. Y en más de una oportunidad recalcó la función política de lxs educadorxs.

Elaboró y llevó a cabo una pedagogía dialógica, que no maneja un discurso unidireccional, que no plantea solo preguntas retóricas socráticas para las cuales el/la docente ya tiene las respuestas, sino que incluye también preguntas sobre lo que el/la docente quiere conocer y aprender, y en las que se devela su propia ignorancia. Un diálogo en el cual educador y educando aprenden uno del otro y se transforman mutuamente. Un diálogo que permita construir una síntesis cultural, idea que también había desplegado Gramsci al proponer la confluencia de docentes, estudiantes y ambiente en un universo común de significados.

A diferencia de esta construcción conceptual, encontramos en la actualidad una proliferación de ofertas de moda sobre la formación de líderes, ${ }^{14}$ siempre más cerca del adiestramiento y la manipulación que de la concientización, más cerca de la competitividad que de la colaboración.

\section{Una reflexión dialogal}

La propuesta de horizontalidad de la relación pedagógica de Freire, que él mismo discutió y reformuló en distintos momentos, revolucionó la pedagogía moderna al minar

14 Como ejemplos, el Gobierno de la Ciudad de Buenos Aires ofreció el Programa “Elegí enseñar”, dirigido a estudiantes secundarios mayores de 16 años para su formación como líderes educativos de la escuela Secundaria del Futuro. La Escuela de Maestros de la Ciudad de Buenos Aires, que se ocupa de la capacitación docente, presentó un Programa de un año de Formación en Liderazgo y Gestión, destinado a docentes que aspiren a desempeñarse en cargos directivos. Y el Centro de E-Learning, de la Universidad Tecnológica Nacional, Regional Buenos Aires, desarrolla una “Diplomatura de liderazgo y competencias directivas para el mundo del trabajo". Entre sus contenidos se encuentran temas como las cualidades del líder, las formas de gestión del liderazgo, la inteligencia emocional, las relaciones poder, comunicación y creatividad. 
la relación pedagógica basada en el saber de quien enseña y la falta de quien aprende. Conserva la fuerza de una hipótesis dirigida a buscar siempre el saber de quien aprende y el aprendizaje de quien enseña. En palabras de Marx, nos recuerda que el problema pedagógico principal es cómo se educa el educador (Hillert, 2001).

Como hipótesis, la horizontalidad propuesta por Freire tuvo un valor tan desafiante como el de Rancière cuando afirmó que todas las inteligencias son iguales. Y si avanzar en la igualdad es una de las tareas pendientes de nuestro tiempo, Rancière nos diría que la igualdad nunca viene después, como resultado, sino que hay que ubicarla antes, como prerrequisito de trabajo.

Freire tuvo la sabiduría de argumentar que alumnx y docente no son iguales; sabemos que tampoco las inteligencias son iguales. Pero como supuestos de actividad, abren senderos de igualdad en el campo educativo.

Desde un discurso filosófico y político más general, Laclau apuntó que ninguna sociedad es homogénea, que existen diferencias de intereses, desniveles, choques - agregamos por nuestra parte diferencias de conocimientos y formación- entre grupos y sujetxs sociales. Por eso son necesarios los partidos, lxs líderes y lxs docentes. Y por eso una pedagogía para la igualdad, la fraternidad y la diversidad es una tarea a desplegar en el siglo XXI.

Por último, a la pregunta de cómo se educa el educador, vale como respuesta la siguiente ilustración autobiográfica de Freire acerca de su propia formación, en contacto "con la maldad de los poderosos, con la fragilidad que precisa convertirse en fuerza de los dominados", fueron surgiendo "soldaduras", "ligaduras" y “...' adivinaciones' a las que mi nuevo saber emergiendo en forma crítica dio sentido..." (Freire, 1993: 17). Bella síntesis de posicionamiento ideológico, pensamiento crítico y formas múltiples de conocimiento. 


\section{Bibliografía}

"Assmann, H. (1969). Bibliografía de y sobre Paulo Freire. En Pedagogía del Oprimido, Buenos Aires, Siglo XXI.

» Barreiro, J. (1998). Educación y concienciación. En La educación como práctica de la libertad. Buenos Aires, Siglo XXI.

"Carbonell, J. (2017). En el centenario de la revolución rusa. 1. El proyecto educativo bolchevique: la escuela única del trabajo. 11 de octubre. Disponible en:

» https://eldiariodelaeducacion.com/pedagogiasxxi/2017/10/11/en-el-centenario-dela-revolucion-rusa-

》CELAM, Documento de Medellín (1968). Disponible en: www.diocese-braga.pt > biblioteca > publicacoes_online

"Escudero, S. E. (2018). Juan XXIII, promotor del diálogo entre católicos y marxistas. Disponible en: https://comercioyjusticia.info/blog/opinion/juan-xxiii-promotor-deldialogo-entre-catolicos-y-marxistas/ (Consultado el 22-08-2018)

" Faure, E. (1975). La explosión educativa. Barcelona, Salvat.

" Fiori, E. M. (1969). Aprender a decir su palabra. El método de alfabetización del Profesor Paulo Freire. En Pedagogía del Oprimido. Buenos Aires, Siglo XXI.

» Freire, P. (1973a). ¿Extensión o comunicación? La concientización en el medio rural. Buenos Aires, Siglo XXI.

»Freire, P. (1973b [1970]). Pedagogía del Oprimido, 1ㅡㄹ. Buenos Aires, Siglo XXI.

»Freire, P. (1993). Pedagogía de la Esperanza. Buenos Aires, Siglo XXI.

»Freire, P. (1998 [1969]) La educación como práctica de la libertad. Buenos Aires, Siglo XXI.

》Freire, P. (2004). Cartas a quien pretende enseñar. Buenos Aires, Siglo XXI.

"Freire, P. (2001). Educación y actualidad brasilera. Buenos Aires, Siglo XXI.

"Gajardo, M. (2016). Paulo Freire sin Barba. Crónica de sus años en Chile. Disponible en: https://www.academia.edu/37282505/Paulo_Freire_sin_Barba_Cronica_de_ sus_a\%CC $3 \%$ B10s_en_Chile

"Germani, G. y Graciarena, J. (1964). De la sociedad tradicional a la sociedad de masas. Buenos Aires, Eudeba.

» Gramsci, A. (1975a). El Materialismo Histórico y la Filosofía de B. Croce. México, Juan Pablos Editor.

»Freire, P. (1975b). Notas sobre Maquiavelo, sobre política y sobre el Estado Moderno. México, Juan Pablos Editor.

» Guyot, V. (1969). Libertad, trascendencia e historia en el diálogo marxista-cristiano. Tarea, 2, 129-144. Memoria Académica. Disponible en: http://www.memoria.fahce. unlp.edu.ar/art_revistas/pr.1138/pr.1138.pdf

" Habermas, J. (1987 [1981]). Teoría de la acción comunicativa. Buenos Aires, Taurus.

» Hillert, F. M. (2001, 23/11) ¿Quién educará al educador? Ponencia. Congreso Internacional "Actualidad y prospectiva del pensamiento pedagógico de Paulo Freire“. Tandil, Universidad Nacional del Centro de la Provincia de Buenos Aires. 
» Hillert, F. M. (2007, 6-9/11). La Tercera Tesis y el debate Freire-Lenin. Ponencia. “Vo Coloquio Internacional Marx y Engels”, Centro de Estudios Marxistas (Cemarx), Instituto de Filosofia y Ciencias Humanas (IFCH). San Pablo, Unicamp. Disponible en: www.unicamp.br/cemarx/anais_v_coloquio_arquivos/paginas/gtssessao4.html

»Hillert, F. M. (2008, mayo). El giro copernicano pedagógico de Freire. Revista Novedades Educativas № 209: 9-13.

» Hillert, F. M. (2011). Políticas Curriculares: sujetos sociales y conocimiento escolar en los vaivenes de lo público y lo privado. Buenos Aires, Colihue.

» Hillert, F. M. (2012, septiembre). Pedagogía y praxis, estudio de autores: "Gramsci y la Educación”, Seminario "Aportes de Gramsci y Freire a la praxis pedagógica”. Tilcara, Maestría en Pedagogías Críticas y Problemáticas Socioeducativas, Facultad de Filosofía y Letras, UBA.

» Hillert, F. M. (2013, agosto-noviembre). Debates sobre populismo en educación: de Tolstoy a Freire. Seminario de grado del Area Focalizada de Teoría de la Educación. Carrera de Ciencias de la Educación, Facultad de Filosofía y Letras, UBA.

» Hobsbawm, E. (1997). Historia del siglo XX: 1914-1991. Buenos Aires, Crítica.

» Jauretche, A. (1973 [1967]). Los profetas del odio y la yapa. La colonización pedagógica. Segunda parte. Buenos Aires, A. Peña Lillo Editor.

» Kant, E. (1993 [1788]). Crítica de la Razón Práctica. Buenos Aires, Losada.

» Kusch, R. (2000). Geocultura del hombre americano. En Obras completas, Tomo III. Buenos Aires, Fundación Ross.

»Laclau, E. (1996). Emancipación y diferencia. Buenos Aires, Ariel.

» Lenin, V. I. (1959 [1902]). Qué Hacer. Obras Completas, Tomo V. Buenos Aires, Cartago.

» Mariátegui, J. C. (1979). El factor religioso. En 7 Ensayos de interpretación de la realidad peruana, Biblioteca Ayacucho. (1928)

» Mujica, C. (1965). Disponible en http://cedinpe.unsam.edu.ar/content/rosales-juanmugica-carlos-nadra-fernando-y-tedeschi-guillermo-argentina-65-di\% $\mathrm{C}_{3} \% \mathrm{~A}_{1}$ logoentre

» Marx, C. (1973 [1845-1846]). Tesis sobre Feüerbach. En Marx, C. y Engels, F. Obras Escogidas, Tomo IV., Buenos Aires, Ciencias del Hombre.

»Paiva, V. (1982). Paulo Freire y el nacionalismo desarrollista. México, Extenporáneos.

» Popper, K. (1945). La sociedad abierta y sus enemigos. Barcelona, Paidós.

» Rancière, J. (2003). El maestro ignorante. Barcelona, Laertes.

"Rodríguez, L. (2004). Producción y transmisión del conocimiento en Freire. En Gadotti, M.; Gómez, M. V. y Freire L. (comps.). Lecciones de Paulo Freire. Cruzando fronteras: Experiencias que se completan. Buenos Aires, CLACSO.

»Rodríguez, L. (2015). Paulo Freire. Una biografía intelectual: Surgimiento y maduración de la pedagogía del oprimido. Buenos Aires, Colihue.

» Rosales, J.; Mugica, C.; Nadra, F. y Tedeschi, G. (1965). Diálogo entre católicos y marxistas. Buenos Aires, Ediciones del Diálogo. Disponible en: http://cedinpe. unsam.edu.ar/content/rosales-juan-mugica-carlos-nadra-fernando-y-tedeschiguillermo-argentina-65-di\% $\mathrm{C}_{3} \% \mathrm{~A}_{1}$ logo-entre

»Snyders, G. (1979). La actitud de izquierda en pedagogía. México, Ediciones de Cultura Popular. 
"Tatián, D (2017). Un mundo sin docentes. Buenos Aires, Página12, 25 de abril.

"Torres, C. A. (1995). Estudios freireanos, Buenos Aires, Libros del Quirquincho.

\section{Flora M. Hillert}

Doctora en Educación, Universidad de Buenos Aires; Magister en Ciencias Sociales con Orientación en Educación, Facultad Latinoamericana de Ciencias Sociales (Argentina); Profesora Titular Consulta del Departamento de Ciencias de la Educación e Investigadora del Instituto de Investigaciones en Ciencias de la Educación (IICE), Facultad de Filosofía y Letras, Universidad de Buenos Aires. fmhillert@gmail.com 
